\title{
A REVIEW ON SOLID SELECTIVE CATALYTIC REDUCTION FOR POST COMBUSTION NOx REDUCTION IN CI ENGINES
}

\author{
Manoj Yadav $^{1}$ and Ajay srivastava ${ }^{1}$ \\ ${ }^{1} \mathrm{UPES}$
}

July 22, 2020

\begin{abstract}
Increasing rate of pollution is a matter of global concern nowadays. One of the major sources of pollution is found to be the combustion products of diesel engine containing hazardous gases like carbon mono oxide, carbon di oxide, unburnt hydrocarbons and oxides of nitrogen. NOx reduction from exhaust of diesel engines is the topic of research for automobile Manufacturers nowdays. Lean NOx trap was used for a long time for this purpose but it was not successful. Then SCR technology came into existence which was found to be the very effective Technology for reduction of nitrogen oxides from diesel engine exhaust. This paper involves the study of a better NOx reduction technology called solid selective catalyst reduction (SSCR). After analysis the results of various experiments it is concluded that NOx reduction efficiency of about $95 \%$ can be easily achieved using SSCR system.
\end{abstract}

\section{Hosted file}

review aiche.pdf available at https://authorea.com/users/345363/articles/471609-a-review-onsolid-selective-catalytic-reduction-for-post-combustion-nox-reduction-in-ci-engines 